\title{
ALGUNAS REFLEXIONES SOBRE LA LITERATURA DE WALTER BENJAMIN COMO UN ANTECEDENTE DE LOS ESTUDIOS SOBRE LA MEMORIA ${ }^{1}$
}

\author{
Victoria Pérez \\ Benemérita Universidad Autónoma de Puebla (México) \\ vita_ru@hotmail.com \\ Gerardo Báez Peralta \\ Benemérita Universidad Autónoma de Puebla (México) \\ baezgeralta@hotmail.com
}

Recibido: 11/02/2020 - Aprobado: 15/04/2020

DOI: doi.org/10.17533/udea.lyl.n78a17

\begin{abstract}
Resumen: Los estudios sobre la memoria han contribuido a clarificar la forma en que la identidad está configurada por nuestros recuerdos, a su vez cimentados y transmitidos en un plano social. En este artículo, revisamos dos ensayos de Walter Benjamin, precursor en la discusión del carácter social de la memoria y del origen, realización y efectos de la rememoración, y los empleamos para reflexionar sobre la naturaleza de la literatura tal y como se la concibe cuando contribuye a la labor de representar y difundir imágenes de enclaves del pasado y a reflexionar sobre los procesos de la memoria colectiva.
\end{abstract}

Palabras clave: memoria colectiva; identidad; Walter Benjamin; naturaleza de la literatura; pasado.

\section{SOME REFLECTIONS ON WALTER BENJAMIN'S LITERATURE AS A BACKGROUND TO THE STUDIES ON MEMORY}

\begin{abstract}
Studies on memory have helped clarify how identity is shaped by our memories, in turn cemented and transmitted on a social level. In this article, we review two essays by Walter Benjamin, a precursor in discussing the social character of memory and origin, realization and effects of remembrance, and use them to
\end{abstract}

1. La investigación titulada La configuración del tiempo y la construcción de identidades narrativas en la escritura de memorias, es un estudio con un enfoque hermenéutico, de la manera en que la construcción narrativa de la identidad está determinada por la configuración de la temporalidad en tres libros de memorias. Se partió del postulado de que son los recursos narrativos y la temporalidad configurada por ellos los que permiten dar un sentido dinámico al concepto de identidad narrativa. 
reflect on the nature of literature as it is conceived when it contributes to the work of depicting and disseminating images of enclaves of the past and reflecting on the processes of collective memory.

Key words: collective memory; identity; Walter Benjamin; nature of literature; past.

\section{Introducción}

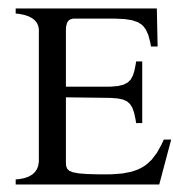

n los últimos años, la memoria colectiva ha acaparado tanta atención que su estudio ha rebasado los ámbitos académicos y permea la sociedad en su conjunto.

Esta trascendencia ha llevado a Astrid Erll (2012), una académica e investigadora alemana, a preguntarse por qué un teórico de la literatura, un historiador de la cultura o un sociólogo se siente atraído por realizar una investigación sobre la memoria y sobre el papel que esta juega en la cultura y la vida social.

Para responder a esta pregunta se requiere considerar una pluralidad de causas. Por principio de cuentas, hoy se sabe que, mediante la memoria, como actividad cerebral, puede representarse el mundo de una forma organizada (Pozo, 2001). Esta capacidad de ejercer la memoria, además, cobra mayor profundidad y alcance al engarzar con la particular condición humana de seres sociales, que viven en comunidades. Moore (2003), añadió lo siguiente al respecto:

[...] los recuerdos que constituyen nuestra identidad y proporcionan el contexto para cada pensamiento y acción no solo son nuestros, sino que también los aprendemos, tomamos y heredamos en parte de unas reservas comunes, construidas, sostenidas y transmitidas por las familias, las comunidades y las culturas a las que pertenecemos (Moore, citado por Fentress \& Wickham, 2003, p. 12).

Reflexionando en lo anterior, se puede deducir que los estudios sobre la memoria tienen el potencial para involucrarse en «una tarea importante de observación reflexiva y de compañía terapéutica de procesos sociales y políticos» (Assman, 2002, p. 45; citado por Erll, 2012, p. 6).

Existen más factores por los que el tema de la memoria acapara la atención, entre ellos habría que considerar la conexión emocional de todo individuo con algún momento del pasado y la recurrencia cada cierto tiempo de una inclinación por los tiempos pretéritos, por ejemplo, con la aparición del romanticismo (Xirau, 2000); podría ser, además, que el futuro 
ya no nos genera tanta ilusión. La nostalgia sería entonces «una emoción propia de las sociedades posmodernas» (Fanjul, 2019).

Las transformaciones en los ámbitos científico y tecnológico desempeñan también un papel importante en el auge de los estudios sobre la memoria, pues la tecnología hace más asequibles este tipo de estudios gracias, entre otras cosas, a la digitalización de los archivos históricos.

Finalmente, es necesario señalar los diferentes procesos históricos que transformaron el tejido social en distintos ámbitos: la transmisión oral de los testimonios de los sobrevivientes de la Segunda Guerra Mundial y el Holocausto se interrumpió y quedó limitada a una investigación histórico-científica y a su tratamiento en los medios de comunicación. También, tras el fin de la Guerra Fría, aparecieron la descolonización y los movimientos migratorios, que derivaron en una creciente multiculturalidad del recuerdo (Erll, 2012). Igualmente, ante la disyuntiva de ciertas sociedades de lidiar con eventos traumáticos del pasado, los estudios sobre la memoria se ven empujados a una labor concreta y demandante.

Las circunstancias que han derivado en este auge de los estudios sobre la memoria nos ayudan a entrever los elementos que, en un momento dado, pueden entrar en el ámbito de lo que Erll (2012) llama «el campo de trabajo de la memoria colectiva y las culturas del recuerdo». En dichos estudios — señala esta investigadora- se examina «la retórica antigua y las bibliotecas de la Edad Media, las tradiciones nacionales y la vivencia de la guerra, el fenómeno generacional y la autobiografía, y finalmente, las discusiones sobre los monumentos conmemorativos y las conexiones neuronales» (p. 11).

Podemos ver que el estudio de la memoria, en un sentido amplio, considera posible relacionar eventos distanciados temática, histórica y geográficamente hablando. En el mundo académico, la memoria, así considerada, se estudia en disciplinas como la psicología cognitiva, las neurociencias, la antropología, la literatura, la historia y también, cuando se estudia la relación entre cultura y memoria, se recurre a los estudios religiosos, la sociología, la historia del arte, la pedagogía y la psicología. Ante ello, se evidencia la necesidad de coordenadas centrales del recordar colectivo, coordenadas que, según Erll (2012) podrían hallarse en conceptos como religión, ideología, etnia y sexo. De hecho, 
existen intersecciones como la unión entre los conceptos de género y memoria, que permiten brindar luz sobre la experiencia femenina y su «papel subversivo, transformador, atípico» (Calderón, Kumor \& Moszczyńska-Dürst, 2015, p. 7), tantas veces escamoteado por la historiografía oficial.

¿Qué tan factible resulta una sobre abundancia de temas y manifestaciones de interés por la memoria? En relación con lo anterior, se podría mencionar que los estudios sobre la memoria pueden ser muy provechosos para un intento de unificación de la referencia al pasado y brindar así un soporte más sólido a los medios de vivificación del pasado, pues con el estudio de las fuentes y el uso de la crítica textual se puede contribuir a un estudio científico de lo transmitido. De momento, se perfilan algunas prácticas políticas y estéticas. En cuanto a la práctica política, se podría investigar el modo en que varía la puesta en juego de la memoria «según cómo se acople [...] a los desafíos del presente» (Calveiro, 2006, p. 379) y examinar cómo se construyen relatos acerca del pasado, pues este puede ser «resistente o funcional al poder» (ibidem). De otro lado, investigaciones sobre las manifestaciones de la narratividad en la vida cotidiana han registrado un componente estético presente cuando los individuos crean y dotan de significado a los hechos vividos (Soto, 2014).

Los estudios sobre la memoria también pueden contribuir con posibles aportes a la construcción historiográfica (Acuña, 2014), al evidenciar el carácter moldeable y narrativo de la historia escrita. Hoy se presencia el socavamiento de la imagen de la historia como algo monolítico. Además, ha ocurrido una reconsideración de las fronteras tradicionales de las ciencias sociales, las artes y las letras (años noventa del siglo pasado) y se han producido reflexiones sobre la graduación entre pasado y presente, universalismo y particularismo y multiculturalismo frente a universalidad (Wallerstein, 2007).

Si algo puede notarse revisando los estudios sobre la memoria es que los debates en torno su papel y tratamiento son recurrentes. Como ejemplo, puede hacerse referencia al debate en la antigua República Federal de Alemania sobre cómo interpretar el devenir político alemán durante el nazismo. Esta discusión llevó a Jürgen Habermas a reflexionar sobre el uso público de la historia: «¿de qué manera se da cuenta del periodo 
nacionalsocialista en la conciencia pública?», se preguntaba este filósofo alemán (2007, p. 77).

Los estudios de la memoria conceden un significado relevante al ejercicio de la literatura que se ve como componente activo de lo que Erll llamó «una cultura del recuerdo» (2012, p. 11). Esta forma artística hace parte de ese grupo de procesos de tipo orgánico, mediales e institucionales, cuyo significado manifiesta el modo como lo pasado y lo presente establecen relaciones, en ambas direcciones, en contextos socioculturales. La forma de concebir la literatura en los estudios sobre la memoria implica distinguirla de otras formas simbólicas, como la religión y el mito.

Ahora bien, la figura de Walter Benjamin no debería considerarse como la de alguien que discierne la naturaleza de lo literario dentro de la teoría de la narrativa. Debe verse como ocupando «un lugar solitario»(Oyarzún, 2008, p. 7). En su ensayo La tarea del traductor (1996), este filósofo alemán afirmó que ninguna obra de arte está orientada a un lector, así que sus planteamientos no se adhirieron a la concepción de un emisor, un mensaje y un receptor o a la noción de lo convencional en el lenguaje o a teorías como la estética de la recepción. ¿De qué manera se puede recurrir a su obra para plantear el significado que la literatura tiene en la comprensión de los esfuerzos y los problemas de los estudios sobre la memoria?

Para responder a esta pregunta, en este artículo se tomó como punto de partida el trabajo de Benjamin (2008) en el que partió de reflexionar sobre cuestiones literarias para plantear aspectos de la transmisión de la propia experiencia y de lo que un miembro de una colectividad pudo escuchar. Luego de ello, se revisarán los intentos de definición de los estudios sobre la memoria y se ubicarán, dentro de dicho campo, la forma en que se ha conceptualizado la literatura como medio de la memoria colectiva. Así, el objetivo consiste en reflexionar sobre los vínculos y diferenciaciones entre esta conceptualización y el trabajo de Benjamin.

\section{Walter Benjamin y la pérdida de la experiencia de la comunicación}


En un ensayo denominado El Narrador. Consideraciones sobre la obra de Nikolas Léskov (2008), Walter Benjamin dedicó su atención a la obra de este escritor ruso de la segunda mitad del siglo XIX; sin embargo, su finalidad no es considerar dicha obra como objeto literario. Benjamin partió de una consideración de la actividad de la narración como «praxis social»(Oyarzun, 2008, p. 8). Sobre esa base, planteó el deterioro de la capacidad de intercambiar experiencias. En definitiva, su objetivo fue considerar la obra de Léskov en términos de una: «instancia en que puede ser ejemplarmente examinada la catástrofe de la experiencia en el mundo moderno» (Oyarzun, 2008, p. 9).

Al investigar el contexto en que se da la aparición de este ensayo, se destaca un cambio en las formas de expresión artística y en la manera de concebir la naturaleza de la obra de arte. En esos años (década de los treinta del siglo pasado) tuvo lugar la exhibición Abstract and Concrete, primera exhibición internacional de arte abstracto en Gran Bretaña con obra de artistas como Mondrian, Kandinsky, Giacometti, Miró, Calder y Moore, entre otros. También tuvo lugar por entonces la London International Surrealist Exhibition, con obra de André Breton y Gala Dali. Como siempre ocurre, estas transformaciones estéticas reflejaban cambios de naturaleza política y social, en las sociedades europeas de la época (Zamora, 2004).

En ese sentido, el trabajo de Benjamin acusó el impacto de esos cambios, al desarrollar una reflexión sobre la industrialización del trabajo y la comunicación de masas. Este filósofo alemán planteó al respecto el caso paradigmático del cambio de la labor de un artesano al trabajo de un obrero. La razón del interés de Benjamin por la obra de Léskov estribó en que la artesanía y los artesanos proporcionaron temas para las narraciones de este narrador ruso. Algunas actividades, como la cerámica y el tejido, que conllevan un contacto físico con el material trabajado, son ensalzadas a lo largo del ensayo mencionado anteriormente (Leslie, 1998).

Otro rasgo que Benjamin enfatiza en Léskov es la figura de los justos, «que encarnan la sabiduría, la bondad, el consuelo del mundo» (2008, p. 88) y que son figuras que cobran forma por lo cercano al mito que parecen estar. Benjamin también reflexiona sobre los efectos de la desaparición del arte de narrar en la novela. 
En su argumentación, Benjamin concibió una lejanía entre la figura del narrador (Léskov) y aquellos que posan una mirada en él. Dado que Léskov es presentado a los lectores por medio del lenguaje escrito que se implementa para dar forma a una disertación y no se establece contacto con él cara a cara, se establece una distancia: «Presentar a un Léskov, como narrador, no quiere decir aproximárnoslo sino más bien aumentar la distancia que de él nos separa» (2008, p. 59). De este modo, la reflexión presentada en El narrador siempre está articulada alrededor de un efecto de mayor o menor lejanía: «Considerado desde una determinada lejanía, los grandes y simples rasgos que constituyen el narrador se imponen en él» (ibidem).

El ambiente del narrador es el del artesano, una figura emblemática que conoce el tiempo y el pasado, que además condensa la experiencia y sabiduría heredadas. A partir del bagaje de este artesano, consistente en un conocimiento práctico que halla su origen en la experiencia del viaje y en la vida de la aldea, cristaliza la memoria cuando sus relatos orales son escuchados, puestos en común y conservados (Seydel, 2014). Se trata de actos que conllevan «formas de participación en una experiencia común, la cual, sin embargo, no está pre-constituida, sino que deviene común en la comunicación y en virtud de ella» (Oyarzun, 2008, p. 13). Pero siempre se apreciará a este narrador un paso más allá de nosotros, como suele ocurrir con las ceremonias litúrgicas: «El narrador — por familiar que nos suene ese nombre - no está de ningún modo presente para nosotros en su vívida eficacia. Nos resulta algo alejado ya y que sigue alejándose» (Benjamin, 2008, p. 59).

Según Benjamin, la facultad de intercambiar experiencias, aquello que solo es obtenido mediante una labor como la de tipo artesanal, está desapareciendo.

El menoscabo de este tipo de experiencia, que Benjamin parecería visualizar como una forma de aproximación trascendente (Gonzáles, 2003), tiene su correlato en la desmitificación de las obras artísticas y los rituales: la lejanía fue siempre un elemento esencial del arte. Una obra de arte se instauraba por la capacidad de quien la apreciaba de estar un paso por detrás de esa obra. El decir de la obra desde una lejanía vinculaba estrechamente la obra de arte y el ritual, por eso es por lo que ciertos credos religiosos han tenido al arte como modo de expresión (Ciudadano 014, 25 de diciembre de 2011). Este vínculo entre la obra artística y los actos rituales Benjamin lo plantea con la noción de aura 
(Robinson, 2013): «works of art had an «aura» an appearance of magical or supernatural force arising from their uniqueness (similar to mana). The aura includes a sensory experience of distance between the reader and the work of art» $(\S 2)$.

Esta experiencia que cristaliza con las obras de arte y los rituales ha sido anulada por una modernidad desbordada de actividad que hace que el interés del sujeto, urgido por esa preeminencia, se dirija hacia otra parte.

Otro aspecto más atañe al predominio de la técnica, lo cual se ve en la guerra, acto brutal absolutamente despersonalizado, que arrastra a sus supervivientes a un enmudecimiento. La guerra y la hiperactividad de las sociedades industriales ponen en escena una manipulación técnica de la naturaleza y del hombre (Cuesta, 2009). En este panorama, ha tenido lugar la desaparición del arte de narrar desplazada por «una nueva forma de experiencia del espíritu atravesada por la complejidad de las relaciones del mundo moderno» (Cuesta, 2009, p. 1). Esta obturación de la posibilidad de comunicar la experiencia es también la anulación de la posibilidad de que, mediante una comunicación, por la virtud del contenido de la narración y de una escucha compartida, se llegue a un devenir común para la pluralidad de los seres humanos.

Existe otro ensayo de Benjamin donde la noción de experiencia se convierte en objeto de interés innegable. Se trata del ensayo titulado Sobre algunos motivos en Baudelaire (2008). En dicho trabajo, Benjamin indicó que el libro de poemas Les fleurs du mal (1999), de Baudelaire, puede ser útil para entreverar el fenómeno de la experiencia por la forma en que este poeta francés se imagina la figura de su lector, en el contexto de condiciones para la acogida de la poesía lírica que son poco favorables: la poesía lírica casi no conserva el contacto con la experiencia de los lectores, o quizá algo pudo transformarse en ella. Para dilucidar este dilema, hay que interrogar a la filosofía y al hacerlo, se descubre que, desde finales del siglo XIX, ésta ha intentado hacerse cargo de la experiencia «verdadera», «en contraposición a esa experiencia que se sedimenta en la existencia, normalizada y desnaturalizada, de las masas ya civilizadas» (Benjamin, 2008, p. 207).

Una obra que puede ser útil para arrojar luz sobre estas posibles transformaciones es Matière et mémoire (1939), de Henri Bergson, en donde «la memoria se considera decisiva para la estructura filosófica de la experiencia»(Benjamin, 2008, pp. 209-210). En esta 
propuesta no se considera la determinación histórica pero sí se establece la esencia de la experiencia en la duración. Al notar lo anterior, Benjamin concluyó que si hay alguien adecuado para ilustrar una experiencia de este tipo no es otro que el narrador francés Marcel Proust. Su obra, A la recherche du temps perdu, puede verse como el intento de producir la experiencia como Bergson la concibió.

De acuerdo con Peller (2010), Proust realzó la oposición planteada por Bergson, entre la vida activa y la vida contemplativa, por lo que convierte la memoria pura de Bergson en memoria involuntaria.

Para Benjamin, la experiencia está formada con datos que se acumulan en gran parte de manera inconsciente. Dicha cualidad inconsciente hace surgir el recuerdo mediante la evocación: un hecho trivial desencadena el recuerdo y entonces, de manera inesperada y azarosa, se recupera el pasado que emerge y permite el enriquecimiento de la experiencia.

La memoria voluntaria, por su parte, está orientada por la consciencia, la cual interviene en el modo en que se visualizan los acontecimientos y hace imposible que emerja el recuerdo capaz de producir experiencia. La memoria voluntaria, por su parte, informa sobre el pasado sin hacerlo revivir, ya que cuando el recuerdo es buscado de forma consciente, la actividad de reflexión se halla bajo el dominio de la inteligencia y los acontecimientos se tornan en experiencia vivida (Peller, 2010). Lo que sucede en ese caso es que el recuerdo buscado de forma consciente retiene lo que obedece a una solicitud de atención. En las primeras páginas de $A$ la recherche du temps perdu Proust afirmó que la ciudad de Combray, donde había pasado una parte importante de su infancia, se ofrecía de manera muy limitada a su memoria hasta que, una tarde, el sabor de una madeleine le remontará a aquel tiempo de una forma diferente.

El desastre de la experiencia en el mundo moderno y la naturaleza del recuerdo involuntario son dos de las latitudes más relevantes de la obra de Walter Benjamin, una obra que cobra sentido de unidad cuando se mira desde la perspectiva de su crítica a la historia como registro escrito de lo que, una vez acontecido, se considera relevante.

Por eso, la idea de Benjamin de la historia atiende a lo siguiente: no se puede fijar el pasado y disponerlo para su conocimiento pues el pasado tiene vida propia (autonomía), acomete a la conciencia y la reaviva; el pasado se capta por el recuerdo y «no interesa como 
reconstrucción, sino como construcción, para incidir en el presente» (de la Garza, 2007, p. 174).

En lugar de atender a sucesiones de datos, Benjamin recurrió a una imagen, la imagen del ángel de la historia, para plantear que, situado como testigo de un trasiego entre pasado y presente, este ángel vería nada más que una catástrofe a horcajadas de ruinas. Esta imagen significa, según de la Garza (2007), no que Benjamin se haya situado contra el progreso, «sino contra la pretensión de ocultar el fracaso y el sufrimiento, contra la pretensión de considerar que todo vale, en aras del progreso» (p. 175):

La crítica de Benjamin a la idea occidental de historia, fundada en el progreso, no lo lleva al pesimismo, sino a la esperanza como categoría histórica: la redención es posible en cada instante del tiempo, tiempo que es aleatorio y abierto en todo momento a la aparición de la novedad (de la Garza, 2007, p. 173).

En el momento en que se restituye un pasado que no está ya procurado, en ese momento el tiempo se vivifica: «Para captar ese especial pasado que es ruptura y liberación, no hay más camino que el recuerdo, que la memoria, que Metz ha llamado razón anamnética» (de la Garza, 2007, p. 178). Esta razón anamnética a la que de la Garza se refirió implica una preocupación por definir con precisión categorías de percepción de la historia que «sean sensibles a la singularidad y la contingencia» (Ruz, Rosolino \& Schickendantz, 2008, p. 589).

Los planteamientos de Benjamin en ensayos como El Narrador (2008) y Sobre algunos motivos en Baudelaire (2008), han sido señalados como un anticipo de lo que después sería conocido como memoria cultural (Seydel, 2014). En este ámbito, el planteamiento de la catástrofe de la experiencia ha sido recuperado en la forma de una preocupación por los diferentes testimonios que brinda el acontecer de lo cotidiano, las víctimas y miembros de la sociedad que sufren mecanismos de exclusión y marginación, lo cual hace que en este otro ámbito se ponga gran atención en el recuerdo individual. El recuerdo individual se postula y luego selecciona algunos elementos de la multiplicidad de sucesos, procesos, entes y medios del pasado. El recuerdo, así, se comporta de manera selectiva.

La memoria cultural tiene como sus fuentes los relatos orales y la interacción cotidiana, pero también considera otros soportes capaces de recopilar, incluir y divulgar las versiones 
del pasado de forma diferente a como Benjamin vislumbró. Maurice Halbwachs exploró los marcos sociales de la rememoración y concluyó que estos brindan elementos para dar forma a los recuerdos individuales: «las personas con las que el individuo interactúa proporcionan fechas, nombres, hechos, nociones espacio-temporales así como mentalidades, patrones de experiencias, de razonar y pensar». (Seydel, 2014, p. 194). Junto a lo anterior, resulta indispensable la acción del simbolismo para interpretar y ordenar los sucesos cuando se rememoran y los mecanismos propios de instituciones y medios para la estabilización de la memoria cultural. Por su parte, Astrid Erll (2012) tomó en cuenta los procesos de dinamización de la memoria cultural, dada la posibilidad de que un público más amplio tenga acceso a la misma a través de medios electrónicos.

De este modo, la manera en que se conceptualizan la memoria y el recuerdo, así como una noción vinculada a ambas como es la experiencia, está determinada actualmente por la presencia de nuevos medios al servicio de la memoria, en el marco de un convencimiento de que la labor más significativa en ese ámbito debería ser articular expresiones de la memoria a las que no se ha concedido atención y cuestionar las versiones hegemónicas del pasado.

Además, la consideración de la literatura como medio al servicio de la memoria se reconfigura por el influjo de un entorno donde las sociedades se tecnifican y se interrelacionan enérgicamente. En la literatura contemporánea y en consonancia con lo que se plantea en los estudios sobre la memoria, estudiosos como Kohut (1997) han hecho notar el valor de la memoria por ser una especie de motor de la literatura. Ese atributo de motor, impulsor o activador está dado por la capacidad de la memoria para activar todo un caudal de simbolismo. Los estudios sobre la memoria pretenden poner en perspectiva este poder de la literatura. Una vía para ello es considerar que la literatura puede llegar a tener el alcance de entender y apresar la historia, no al modo de la historiografía, sino mediante la creación y recuperación de relatos del pasado que posibilitan acceder a un sentido del mundo (Soto, 2014).

A continuación, se centrará la atención en las consideraciones sobre la memoria y el recuerdo, así como en la experiencia y el lugar que ocupa la literatura tal y como se ubican en un lugar dentro de la configuración de los estudios sobre la memoria. 


\section{Los estudios sobre la memoria y la literatura como medio al servicio de la memoria colectiva}

En la parte introductoria a este artículo, se mencionó la necesidad de convergencia en un punto común de las diferentes iniciativas de estudios sobre la memoria. Un punto de partida pueden ser esfuerzos como el de Erll (2012), al apuntalar el fenómeno del recuerdo, en su dimensión sociocultural, haciéndolo pasar a ser objeto de investigación de los estudios culturales y al expresar claramente la aspiración de dar forma a «un modelo integral de la memoria colectiva y de las culturas del recuerdo» (Erll, 2012, p. 11).

Una manera de ampliar el conocimiento de cómo proceden los estudios sobre la memoria es poner atención en un concepto específico que ha tomado forma dentro de este espacio de investigación. Para ello, se hará énfasis en el concepto de memoria colectiva.

Cuando se hace una revisión panorámica de la historia de las investigaciones que se han hecho sobre la memoria en el campo de los estudios culturales, da la impresión de que el concepto de memoria colectiva fue lo primero en tomar forma. Actualmente, este concepto es uno de los más influyentes. La memoria colectiva ha sido definida de la siguiente manera por Erll (2012): «La memoria colectiva es un concepto genérico que cobija todos aquellos procesos de tipo orgánico, medial e institucional, cuyo significado responde al modo como lo pasado y lo presente se influyen recíprocamente en contextos socioculturales» (p. 8). Como puede verse, la definición citada considera procesos de tipo orgánico, como los involucrados en el funcionamiento cerebral, al lado de los medios al servicio de la memoria colectiva y las instituciones que la nutren y que se nutren de ella. La idea es que se pueden considerar todos estos componentes, si hace falta, para aclarar cómo se da la memoria en su manifestación social y cultural. Para esta investigadora, la memoria colectiva representa el contexto total, dentro del cual surgen fenómenos culturales diversos, como el recuerdo individual, la historia o el texto ficticio.

Además, Erll (2012) aclaró que como resultado del interés evidente por el tema de la memoria que ha tenido lugar en las últimas dos décadas, han aparecido multiplicidad de nociones y conceptos, cuyas semejanzas y diferencias no son claras, pero esta investigadora 
advirtió que no se debe prescindir de ninguno de estos conceptos. Así, aledaño al concepto de memoria colectiva están denominaciones como memoria cultural y «praxis del recuerdo» (p. 1), donde el sustantivo praxis puede enfatizar, desde la perspectiva de este estudio, tanto en la acción de recordar en sí misma como en las consecuencias prácticas de «ponerse a recordar».

Otro término que aparece es «cultura del recuerdo» (Erll, 2012, p. 8), apelativo adoptado, entre otros, por Maldonado (2009), quien proveyó la siguiente definición:

Las culturas del recuerdo son variables históricas y culturales de la memoria colectiva de una sociedad, o sea, se asientan en las interpretaciones colectivas del pasado y de la imagen que de sí misma tiene una comunidad. La formación social cuyos integrantes comparten un conjunto específico de recuerdos colectivos constituye una cultura del recuerdo. Ésta aparece determinada por los modelos, normas, valores, ideas, sentimientos, etcétera, vigentes en la sociedad en un momento preciso de su evolución histórica (p. 139).

Puede apreciarse que en cada definición se emplea o privilegia uno u otro concepto. Así, mientras que Erll alude a contextos socioculturales como asiento de las culturas del recuerdo, Maldonado habló, por su parte, de un aspecto comunitario. Finalmente, Erll (2012) da un lugar tanto a la memoria colectiva como a las culturas del recuerdo en el espacio de los estudios culturales: «la memoria colectiva es el centro de la curiosidad existente en el ámbito de los estudios culturales —afirma—, mientras las culturas del recuerdo son su objeto de estudio» (p. 10).

Los estudios sobre la memoria guardan conexión con investigaciones sobre los contextos socioculturales de interpretación, que determinarían la formación de la experiencia. En este marco se analizan, entre otros aspectos, el modo en que, a través del tiempo, se introducen nuevos términos y estructuras de pensamiento desde una lengua a otra (procesos de consolidación y recombinación de las semánticas culturales) y los rasgos de las mediaciones en la comunicación de masas por medio de la tecnología que hacen posibles las experiencias de segunda mano (Erll, 2012). De este modo, los estudios de la memoria también incorporan un interés por el fenómeno de la experiencia como adyacente al concepto de identidad colectiva, entrelazado con el concepto de memoria, fecundado por procesos como la percepción, el recuerdo, la interpretación, la tradición y con una dimensión colectiva y temporal. 
Gracias al trabajo de investigadores como Berger y Luckmann (1997), la experiencia se concibe actualmente como producto de procesos sociales. En esta parte de la exposición, se seguirán los planteamientos de Fraga (2018) sobre el modo en que los sujetos interpretan su entorno, de acuerdo con la perspectiva fenomenológica de Alfred Schütz y Thomas Luckmann, así como la planteada por Berger y Luckmann sobre la construcción social de la realidad.

Para que la conciencia dirija la atención a algo ha de activarse la capacidad de esta, mediante un logro sintético, de configurar un objeto o propósito. Berger y Luckman lo llamaron «objeto intencional» (1997, p. 4). En torno a este objeto intencional se extiende un campo temático cuyo horizonte es abierto o que es, en palabras de Fraga (2018), un «horizonte externo» (p. 4), un horizonte interpretativo en principio infinito. Discernir una situación del mundo social, en función de su horizonte externo, es poner esa situación en relación con otras circunstancias, experiencias y vivencias. Cada individuo tiene también su propia historia subjetiva y su horizonte interno, que puede establecerse sin limitaciones.

Cuando la vivencia subjetiva de la biografía y su planificación objetiva se articulan, los horizontes interno y externo entran en relación entre sí: la duración interior de las experiencias se conjunta con la temporalidad exterior de los planes que uno establece para una jornada determinada, y así se superponen de manera ajustada a los ritmos de la conciencia y los de la acción cotidiana: la marcha de la existencia va siendo interpretada sucesiva y simultáneamente en función de ambos horizontes infinitos y la biografía y los planes del sujeto pueden ser comprendidos como situaciones de acción, con un componente pragmático, y como situaciones ontológicas gracias a sistemas de tipificaciones y valoraciones normativas.

En línea con lo anterior, el horizonte abierto es el fundamento desde el cual puede surgir el sentido, que se integra por secuencias de temas interrelacionados (aprehensiones) que al atraer la atención del yo adquieren un mayor grado de definición temática: se tornan experiencias perfiladas.

La conciencia capta la relación de un núcleo de experiencias con otras experiencias que se separa del trasfondo de aprehensiones. La forma más simple en que establecemos relaciones entre núcleos de experiencias es estableciendo semejanzas, diferencias y 
gradaciones. Así se constituye el nivel más elemental de sentido. El sentido es conciencia del hecho de que existe una relación entre las varias experiencias.

Generalmente, cada experiencia está relacionada con un tipo, esquema, máxima, forma de legitimación moral, etc., producto de muchas experiencias, que quedan almacenados en el saber subjetivo o se toman de las reservas o acumulaciones sociales del conocimiento. Entre esas relaciones se encuentran las que permiten vincular las experiencias actuales con otras del pasado inmediato o distante, al igual que el horizonte de expectativas de una sociedad.

El modelo de memoria colectiva que Erll (2012) propuso presenta una configuración semejante: un aparato psíquico y cultural dentro del cual las experiencias se construyen, se interpretan y se transmiten con la memoria, ocupando un lugar de aparato de selección y esquematización que posibilita las experiencias. La memoria funcionaría como un tipo de archivador en el que se organizan las experiencias tanto prospectivas, con esquemas que ya preforman la experiencia y que definen qué entra en la conciencia del individuo y cómo se elabora esta información, así como retrospectivamente, a través del proceso del recordar.

La experiencia puede verse como una interpretación semiótica que se guía por la acción. En este punto, ocuparía un lugar el recuerdo individual dentro del ámbito de la vivencia personal, que cobra vida cuando se mira interpretativamente hacia el pasado y esa interpretación es convertida en experiencia de vida como resultado del proceso de recordar y, desde el punto de vista de este estudio, en un acto concreto de recuerdo. Luego, o a la par de ello, esa experiencia se convierte en narración.

A su vez, esa narración puede manifestarse en textos que pueden abordarse considerándolos como «programas mnemónicos compactos» (Lotman, 2003, p. 113). Lotman caracteriza a los textos como programas mnemónicos compactos, luego de presentar las tres funciones que se les puede adscribir: comunicativa, creativa y una tercera función «vinculada al problema de la memoria de la cultura» (ibidem): los textos individuales tendrían el potencial de ayudar a reconstituir «capas íntegras de cultura, para restaurar una memoria» (ibídem).

La mención de esas capas íntegras de cultura y de una restauración de la memoria hace recordar un interrogante planteado por Erll (2012): 
¿Cómo pueden la formación de la sociedad, los procesos históricos, la literatura, el arte y los medios otorgar claridad a la perspectiva de la memoria? La respuesta a esta pregunta en el seno de los estudios sobre la memoria es que ello se puede lograr examinando la manera en que la literatura y el arte contemporáneos ponen en escena tanto el recordar como el olvidar, que les sirven de medios, pues la literatura y el arte son prácticas que entran en el ámbito de la memoria como «fenómeno enteramente cultural» (p. 1).

El examen de estas características de la literatura y el arte posibilitaría inferir hipótesis sobre la naturaleza de la memoria colectiva y sobre cómo funciona.

\section{Apuntes sobre la pervivencia de las ideas de Walter Benjamin en la visión de la literatura como medio al servicio de la memoria}

Existe otra vertiente importantísima del trabajo de Benjamin: su propuesta de una violencia de origen cuando mediante el lenguaje se pretende alguna forma de representación. Esta idea aparece en el ensayo Para una crítica de la violencia (1998). Con base en el contenido de este ensayo y de la mano del concepto de suplemento de Jacques Derrida, Pereyra (2016), propuso que es posible formular preguntas sobre la forma en que las minorías se posicionan y establecen vínculos con relación a un grupo hegemónico. La idea de hegemonía también puede vislumbrarse en la posición de Benjamin respecto de lo que se conoce como el canon literario. Así, en La tarea del traductor (1996), Benjamin relacionó el estatuto del canon literario con la tarea de la traducción, al aseverar que la traducción de toda obra de arte es inviable.

Solo puede darse la traducibilidad cuando una traducción corresponde o guarda un respeto significativo hacia la naturaleza o el espíritu de la obra ajena, sobreponiéndose a las costumbres lingüísticas propias y captando cierta significación inherente proveniente de los originales, al establecerse una relación tan íntima que ya no es significativa para el original: se la puede llamar natural, y, con más precisión, una relación de la vida» (Benjamin, 1996, p. 336).

Pero si una obra de arte puede ser traducida, ello conlleva la ironía de que dicha obra ya no podría ser canónica, pues ha podido ser traducida o, en todo caso, la traducción misma debería ser considerada canónica también. El lado más productivo de esta paradoja es que 
puede arribarse a la conclusión de que la tarea de la traducción, cuando se ejerce como Benjamin la plantea, puede cuestionar la idea del canon literario.

Este tipo de disquisiciones llevan a Belforte (2012) a caracterizar la labor analítica de este pensador alemán como aquella que «destruye, mediante la crítica a los conceptos, las unidades semánticas de la tradición que los constituyen» (p. 5). Esta desarticulación de conceptos es seguida por la conformación de entramados conceptuales a partir de componentes desagregados de dicha tradición.

En el caso de los estudios sobre la memoria, la atención concedida a los procesos literarios está determinada por el potencial de la literatura de contribuir a la formación de la memoria y a reflexionar sobre esta. La literatura aparece aquí delineada por rasgos distintivos que obedecen a convenciones de tipo cultural y social a veces anquilosadas, pero también se da cabida a rememoraciones que se manifiestan de modo narrativo en la vida cotidiana.

En las disquisiciones sobre la memoria cultural, la literatura se visualiza como una forma de narrativa de los recuerdos (Ball, 1999), teñida por una activación de la afectividad y envuelta por un aura emotiva que la torna memorable. La obra de Proust muestra que un recuerdo antes adormecido se torna súbitamente en una narración que ofrece solo respuestas de tipo afectivo, demostrando así que, como afirma Ball (1999), la memoria es activa y se ubica en el presente.

La noción de experiencia planteada por Benjamin también se puede considerar arraigada en el presente: se propone que la experiencia es un medio que, desde el presente, posibilitaría incorporar aspectos de lo humano, sin rechazar de manera absoluta lo que concerniese a la tradición.

\section{Conclusiones}

Se han presentado algunas ideas de Walter Benjamin que aparecen en ensayos dedicados a creadores literarios como El Narrador (2008) y Sobre algunos motivos en Baudelaire (2008). Estas ideas pueden verse como anticipo de lo que después sería conocido como memoria cultural (Seydel, 2014). El planteamiento de la catástrofe de la 
experiencia, por ejemplo, ha sido recuperado en la forma de una preocupación por los testimonios surgidos del acontecer de lo cotidiano, de las víctimas y miembros de la sociedad que sufren exclusión y marginación, lo cual hace que en este otro ámbito se ponga gran atención en el recuerdo individual.

El concepto de recuerdo individual está vinculado a las nociones de memoria, recuerdo y experiencia que fueron discutidas por Benjamin y que forman parte de las disquisiciones teóricas de los estudios sobre la memoria. La crítica de Benjamin de este tipo de conceptos permite enfocarlos de modos no convencionales para luego apreciar cómo este filósofo alemán los recuperó en entramados conceptuales que confrontan la tradición.

Al final de este artículo, puede apreciar que los estudios sobre la memoria pueden sacar provecho del trabajo pionero de Benjamin para continuar contribuyendo a aclarar la forma en que la identidad se configura con la manifestación de los recuerdos propios, que a su vez son moldeados por los grupos sociales a los cuales se pertenece.

Además, la ensayística de Benjamin permite apreciar un rasgo que quizá no ha sido suficientemente valorado: la literatura no solo se asoma al pasado, sino que también anticipa el futuro. Esta capacidad de la literatura ha sido señalada por Erll (2012): «La literatura puede, de esta manera, incorporar lo nuevo y lo otro en la cultura del recuerdo» (p. 204).

\section{Referencias bibliográficas}

1. Acuña, O. (2014). El pasado: historia o memoria. Revista Historia y Memoria, 9, 57-87.

2. Ball. M., Crewe, J., \& Spitzer, L. (Eds.). (1999). Acts of Memory. Cultural Recall in the Present. Hanover and London: University Press of New England.

3. Ball, M. (1999). Introduction. En Ball. M.; Crewe, J., \& Spitzer, L. (Eds.), Acts of Memory. Cultural Recall in the Present. Hanover and London: University Press: New England.

4. Baudelaire, Ch. (1999). Les fleurs du mal. Librairie Générale Française.

5. Belforte, M. E. (2012). Los conceptos de memoria, tradición y experiencia en el proyecto político de Walter Benjamin [Disertación doctoral, Universidad de Buenos Aires]. 
6. Benjamin, W. (1996). «La tarea del traductor». Teorías de la traducción. Antología de textos. (Traducción de Hans Christian Hagedorn. Edición de Dámaso López García). Cuenca: Universidad de Castilla La Mancha, 335-347.

7. Benjamin, W. (1998). Para una crítica de la violencia. En Para una crítica de la violencia y otros ensayos. Iluminaciones, IV, 23-47. Madrid: Taurus.

8. Benjamin, W. (2008). El Narrador. Santiago de Chile: Ediciones Metales Pesados.

9. Benjamin, W. (2008). Sobre algunos motivos en Baudelaire. En R. Tiedemann y H. Schweppenhäuser (Eds.), Obras. Libro I. Vol. 2. (pp. 205-259). Madrid: Abada.

10. Benjamin, W. (1997). Modernidad, pluralismo y crisis de sentido ¿Qué necesidades humanas básicas de orientación deben ser satisfechas? Estudios Públicos, 63, 1-54.

11. Berger, P. \& Luckmann, T. (1968). La construcción social de la realidad. Buenos Aires: Amorrortu Editores.

12. Bergson, H. (1939). Matière et mémoire. Essai sur la relation du corps a l'esprit. [Édition électronique] Paris: Les Presses universitaires de France, 1965, 72e édition. Collection: Bibliothèque de philosophie contemporaine.

13. Calderón. A., Kumor, K. \& Moszczyńska-Dürst, K. (2015). Introducción:emoria versus historia. En Calderón. A., Kumor, K. \& Moszczyńska-Dürst, K. (Eds.), La voz dormida? Memoria y género en las literaturas hispánicas (pp. 7-10). Varsovia: Instituto de Estudios Ibéricos e Iberoamericanos de la Universidad de Varsovia.

14. Calveiro, P. (2006). Los usos políticos de la memoria. En Sujetos sociales y nuevas formas de protesta en la historia reciente de América Latina. Buenos Aires: CLACSO, Consejo Latinoamericano de Ciencias Sociales. Recuperado de http://bibliotecavirtual.clacso.org.ar/clacso/gt/20101020020124/12PIICcinco.pdf

15. Caro, M. T. (1999). La escritura del otro. Murcia: Servicio de Publicaciones, Universidad.

16. Caygill, H. (1998). Walter Benjamin. The Colour of Experience. London: Routledge. 17. Ciudadano 014 (25 de diciembre de 2011). La pérdida de aura en la obra reproducida según Walter Benjamin. Recuperado de http://www.lasangredelleonverde.com/la-perdidade-aura-en-la-obra-reproducida-según-walter-benjamin/ 
18. Cuesta, M. (2009). Justicia y narración. Sobre la nueva edición de El narrador, de

Walter Benjamin. Question, 1(21), 1-4. Recuperado de https://www.perio.unlp.edu.ar/ojs/index.php/question/article/view/746/648

19. de la Garza, M. (2007). Tiempo y memoria en Walter Benjamin. En Topografías de la modernidad. El pensamiento de Walter Benjamin (pp. 173-185). México: Universidad Nacional Autónoma de México. Universidad Iberoamericana. Goethe-Institut Mexiko.

20. de Man, P. (1989). «La tarea del traductor» de Walter Benjamin. Acta Poética, 9-10, 257-294.

21. Díaz, L. (2013). Narración y memoria. Anotaciones para una antropología de la catástrofe. Editorial UNED.

22. Echeverría, D. (2005). (Comp.). La mirada del ángel. En torno a las Tesis sobre la historia de Walter Benjamin. México: Facultad de Filosofía y Letras. Universidad Nacional Autónoma de México. Ediciones Era.

23. Echeverría, D. (2005). El ángel de la historia y el materialismo histórico. En La mirada del ángel. En torno a las Tesis sobre la historia de Walter Benjamin. México: Facultad de Filosofía y Letras. Universidad Nacional Autónoma de México. Ediciones Era.

24. Echeverría, D. (2011). Memory in Culture. New York: Palgrave Macmillan.

25. Erll, A. \& Nünning, A. (2005). Where Literature and Memory Meet: Towards a Systematic Approach to the Concepts of Memory Used in Literary Studies. In Grabes H. (Ed.), Literature, Literary History, and Cultural Memory (pp. 261-294). Göttingen: Hubert \& Co.

26. Erll, A. (2012). Memoria colectiva y culturas del recuerdo. Estudio introductorio. Bogotá: Universidad de los Andes.

27. Fanjul, S. (16 de abril de 2019). Por qué nos fascinan Stranger Things y demás guiños al pasado. El País Semanal, IDEAS. Recuperado de https://elpais.com/elpais/2019/04/16/ideas/1555409659_290770.html

28. Fentress, J. \& Wickham, C. (2003). Memoria social. Madrid: Frónesis. Ediciones Cátedra. Universidad de Valencia. 
29. Finkelde, D.; Webels, E.; de la Garza, T. \& Mancera, F. (Coords.) (2007). Topografías de la modernidad. El pensamiento de Walter Benjamin. México: Universidad Nacional Autónoma de México. Universidad Iberoamericana. Goethe-Institut Mexiko.

30. Fraga, E. (2016). Ciencia y experiencia en Schütz y Luckmann. Memoria Académica, IX, Jornadas de Sociología de la UNLP.

31. González, H. (2003). Reflexiones sobre Walter Benjamin: aproximación a la experiencia para abordar otras formas de conocimiento. Revista de Ciencias Sociales, 2(100), 31-47.

32. Habermas, J. (2007). Del uso público de la historia. La quiebra de la visión oficial de la República Federal Alemana. Repositori d'Objectes Digitals er a l'Ensenyament la Recerca $i$ la Cultura, (pp. 77-86). Recuperado de http://deric.uv.es/bitstream/handle/10550/46214/7784.pdf?sequence $=1 \&$ isAllowed $=\mathrm{y}$

33. Kocka, J. (1999). Asymmetrical Historical Comparison: The Case of the German Sonderweg. History and Theory, 38(1), 40-50. https://doi.org/10.1111/00182656.751999075

34. Kohut, K. (1997). La invención del pasado. La novela histórica en el marco de la posmodernidad. Frankfurt. Madrid: Vervuert. Iberoamericana.

35. Leslie, E. (2007). Walter Benjamin. London: Reaktion Books.

36. Leslie, E. (1998). Walter Benjamin: Traces of Craft. Journal of Design History, 11, 513

37. Lotman, I. (2003). Sobre el concepto contemporáneo de texto. Lotman desde América. Entretextos. Revista Electrónica Semestral de Estudios Semióticos de la Cultura, 2(9). Recuperado de http://www.ugr.es/ mcaceres/entretextos/pdf/entre2/entretextos2.pdf 38. Maldonado, M. (2009). La confrontación con el pasado en la narrativa alemana a partir de 1945. En Alemán, M. (Coord.). Literatura e identidad cultural. Representaciones del pasado en la narrativa alemana a partir de 1945. Berna, Berlín, Bruselas: Peter Lang.

39. Mees, L. (1996). La catástrofe alemana y sus historiadores. El fin del régimen nacionalsocialista 50 años después. Historia Contemporánea, 13, 465-486.

40. Moore, R. (2003). Prólogo. En Fentress, J. \& Wickham, C. Memoria social. Madrid: Frónesis. Ediciones Cátedra. Universidad de Valencia. 
41. Morales, L. (2001). La escritura de al lado, Géneros referenciales. Santiago de Chile: Editorial Cuarto Propio. Recuperado de https://books.google.com.mx/books?id=usuYf7ioh08C\&printsec=frontcover\&dq=La+escrit ura+de+al+lado:+g\%C3\% A9neros+referenciales\&hl=de \&sa=X\&ved=0ahUKEwimnsbFpzgAhXAIjQIHb_IBYEQ6AEIKTAA\#v=onepage\&q=La\%20escritura\%20de\%20al\%20lad o\%3A\%20g\%C3\%A9neros\%20referenciales \& $\mathrm{f}=$ true

42. Oyarzun, P. (2008). Preámbulo a El Narrador. Santiago de Chile: Ediciones Metales Pesados.

43. Peller, M. (2010). Un recuerdo de la infancia. juego, experiencia y memoria en los escritos de Walter Benjamin. Nómadas. Critical Journal of Social and Juridical Sciences, 27(3), 1-12.

44. Peña, J. (2002). La poética del tiempo: ética y estética de la narración. Santiago de Chile: Editorial Universitaria. Recuperado de https://books.google.ca/books?hl=de\&lr=id=CCuICMYy2_UC\&oi=fnd\&pg=PA159\&dq=d imensi $\% \mathrm{C} 3 \% \mathrm{~B} 3 \mathrm{n}+$ temporal+configurante+acci\% $\mathrm{C} 3 \% \mathrm{~B} 3 \mathrm{n}+$ eventos+se+convierten+en+his torias\&ots=rZQr5KaqrV\&sig=mqe5bl7FQZYbQGrqAKvSpHaDe9M\#v=onepage\&q\&f=tr ue

45. Pereyra, S. (2016). Ante los restos del multiculturalismo (o la literatura transnacional en alemán hoy). Moderna Språk, 110(1), 83-100.

46. Pozo, J. (2001). Humana mente. El mundo, la conciencia y la carne. Madrid: Ediciones Morata.

47. Richard, N. (2006) (Ed.). Políticas y estéticas de la memoria. Departamento de Santiago, Chile.

48. Robinson, A. (2013). Walter Benjamin: Art, Aura and Authenticity. Recuperado de https://ceasefiremagazine.co.uk/walter-benjamin-art-aura-authenticity

49. Ruz, M.; Rosolino, G. \& Schickendantz, C. (2008). Razón anamnética, sufrimiento ajeno y teodicea. Claves de lectura, logros y límites de la obra de Johann Baptist Metz. Teología y Vida, 49, 575-603.

50. Seydel, U. (2014). La constitución de la memoria cultural. Acta Poética, 35(2), 187214. 
51. Soto, M. (2017) (Comp.). Habitar y narrar. Ciudad Autónoma de Buenos Aires: Eudeba.

52. Wallerstein, I. (Coord.) (2007). Abrir las ciencias sociales. México: Buenos Aires; Madrid: Siglo XXI Editores.

53. Xirau, R. (2000). Introducción a la historia de la filosofía. México: Universidad Nacional Autónoma de México.

54. Zamora, M. (2004). Walter Benjamin: la obra de arte en la época de su reproductibilidad técnica. Fedro, Revista de Estética y Teoría de las Artes, 1, 40-53. 